\title{
Comparison based Performance Analysis of UDP/CBR and TCP/FTP Traffic under AODV Routing Protocol in MANET
}

\author{
Ritika Sharma \\ Pursuing M.Tech, Dept. of ECE \\ AITR, Mangaliya Square \\ Indore, MP, India
}

\author{
Kamlesh Gupta \\ Associate Prof., Dept. of ECE \\ AITR, Mangaliya Square \\ Indore, MP, India
}

\begin{abstract}
The transmission of information in a MANET relies on the performance of the traffic scenario (application traffic agent and data traffic) used in a network. The traffic scenario determines the reliability and capability of information transmission, which necessitates its performance analysis. The objective of this paper is to compare the performance of TCP/FTP and UDP/CBR traffic in AODV routing protocol generally implemented in a mobile ad hoc environment. An empirical study has been done using NS-2. Exhaustive simulations have been done to analyze results, which are evaluated for performance metrics, such as throughput, packet delivery ratio and average end to end delay. The effect of variations in simulation time, number of nodes, and speed of mobile nodes on the network performance is analyzed over a wide range of their values. It is observed that the TCP/FTP offers a far better performance for throughput than UDP/CBR; in case of PDR, former offers an almost constant trend, whereas the latter shows highly varying (rising and falling) trends in all the three aforementioned scenarios. The average end to end delay of latter is lesser than former. The results follow these trends over a wide range of simulation parameters.
\end{abstract}

\section{General Terms}

Mobile ad hoc network (MANET), topology, protocol, routing, performance metrics

\section{Keywords}

MANET, TCP/FTP, UDP/CBR, AODV, routing protocol, NS-2, throughput, packet delivery ratio, average end to end delay.

\section{INTRODUCTION}

A Mobile Ad Hoc Network (MANET) is a wireless network comprising wireless mobile nodes communicating with one another for some ad hoc purpose. In such networks, there is no fixed infrastructure available; therefore, they are well suited for the infrastructureless environments such as earthquake prone areas, battlefield applications, virtual classrooms, and many emergency services [3, 8]. In such scenarios, MANET's features like mobile nodes, abruptly changing topology, no physical network boundary, communication with the nodes within wireless range, support the need of communication. The MANET imposes several challenges for communication, out of which one of the important challenges is to provide secure and efficient routing of data in the network [1,2, 3, 4, 5]. So, there is a great need to develop dynamic and efficient routing protocols, which can ensure efficient and secure routes for communication. The main objective of this paper is to carry out the performance evaluation of an Ad hoc On demand Distance Vector (AODV) routing protocol for Transmission Control Protocol/File Transmission Protocol (TCP/FTP) and User Datagram Protocol/Constant Bit Rate (UDP/CBR) traffic types, subjected to three varying parameters; simulation time, number or density of node, speed of mobile nodes. These scenarios are tested by exhaustive simulations performed on Network Simulator- Version 2 (NS-2) and the conclusions are drawn based on performance metrics, such as, throughput, packet delivery ratio, and average end to end delay, to evaluate the performance.

\section{RELATED WORK}

This section provides an overview of the latest trends of research going in the field of MANET. This also provides motivation for the beginners who are willing to work in this field. The authors of many research papers have considered routing security a serious issue and have stressed on the working of various routing protocols $[1,2,3,4]$. The current trends as mentioned by some authors in this field suggest the researchers to study the role of MANET in the evolution of future wireless technologies $[4,5]$. Most of the related work available in the literature of MANET includes its challenges and applications as it directs the future of this technology [6, $7,8,9]$. Along with some general trends of research towards MANET, one of the specific areas of research belongs to the traffic scenario analysis. Here different traffic scenarios that are available for a MANET are analyzed under various conditions. The traffic model is subject to various changing environments to which a MANET is generally prone, and then their effects are studied on various performance metrics to analyze network performance when implemented using AODV routing protocol. For AODV routing, many authors have presented the effect of mobility i.e. varying speed of nodes in a MANET on traffic models like TCP and CBR, and have compared their performance for some performance metrics $[10,11,12,13]$. A similar comparison is provided for variable node density and pause time [13, 14, 15]. Researchers have also stressed on comparison between TCP and CBR for different routing protocols [16, 17, 18]. Although various authors in their research have provided a performance based comparative analysis between the two traffic scenarios namely, TCP/FTP and UDP/CBR, a great deal of concatenation is still required to be made in such work too, to provide some more specific results. In this project, efforts have been made to compare the performance of TCP/FTP and $\mathrm{UDP} / \mathrm{CBR}$ under AODV routing protocol, together for most frequent and vulnerable varying parameters to a MANET, like 
simulation or run time of a network, number or density of mobile nodes, and speed of mobile nodes. These variations are made on a wide range of their values; exhaustive simulations are done to provide clear trends for performance metrics like, throughput, packet delivery ratio and average end-to-end delay. All these parameters forming a simulation environment provides basis to verify various characteristics offered by two aforementioned traffic scenarios.

\section{AODV ROUTING PROTOCOL}

The following sections focus on the basic features and functionality that the AODV routing protocol employs to service in a MANET. This may help to get a clear understanding of the routing scheme, which indirectly governs the transmission capability of a network $[2,4,10,12,14,16$, 18].

\subsection{Basic Features}

The basic features are mentioned below:

(a) AODV routing protocol belongs to the category of reactive or on demand routing protocols. In such protocols, the nodes do not update their routing tables periodically, unless new routes are demanded by any network node.

(b) Stimulated by the above feature, such protocols are not suitable for the networks that are highly dynamic, prone to frequent and unpredictable changes.

(c) AODV routing protocol does not initiate route discovery of its own, unless it is requested by some other node that is willing to transmit any data.

(d) In AODV, the life of the routes in routing table of the nodes is until the routes are no longer needed in the network, i.e., if the routes are not used for a specified period of time, they are discarded.

(e) AODV routing protocol offers route to the destination "ondemand".

(f) Here any of the source nodes willing to communicate with the destination node of the network to which it has no route information, so it has to make route discovery before making any transmission.

(g) The route discovery and route maintenance which are the two main responsibilities of AODV routing protocol are done by the use of three types of control messages; Route Request (RREQ), Route Reply (RREP), Route Error (RERR) messages.

(h) From the available choices of route, the sender selects the one offering the shortest path to the destination. If one or more routes are of equal length, then it selects the one offering minimum traffic.

(i) AODV employs destination number as the requested node identity to find routes to the destination. This number is mentioned in the RREQ control message.

(j) Bandwidth in AODV is mainly consumed during the starting of any transmission, but not during the entire transmission.

\subsection{Functionality}

The basic functionality that needs to be understood is the route discovery mechanism employed in AODV. The routes to the destination are traced by using three control messages namely RREQ or query message, RREP and RERR message. These three are explained as follows: (a) RREQ Control Message: AODV starts discovering routes with the RREQ messages. The source node in the network broadcasts or floods these RREQ messages to its neighbouring nodes. The RREQ messages will be propagated in the network in the aforementioned manner at every node, until the destination node in the network is found. The destination will be checked for matching the destination identity or destination sequence number attached in the RREQ message.

(b) RREP Control Message: Once a node matches the destination sequence number, the destination node generates a RREP message and replies the source with the same, through the same route by which the destination was traced.

(c) RERR Control Message: These messages are generated and propagated through the network in the event of link failures occurring in two possibly encountered scenarios; first, link failure during the transmission of RREP messages and second, link failure in the active route during the course of data transmission. In both the cases the RERR message is generated by a node encountering link failure.

\section{PERFORMANCE METRICS}

The performance of any system needs to be evaluated on certain criteria, these criteria then decide the basis of performance of any system. Such parameters are known as performance metrics $[10,13,14,16,18]$. The three types of performance metrics used to evaluate performance of TCP/FTP and UDP/CBR in this paper are described below:

\subsection{Throughput}

The throughput is the measure of how fast we can actually send data through the network. It is the measurement of number of packets that are transmitted through the network in a unit of time. It is desirable to have a network with high throughput.

$$
\text { Throughput }=\frac{\sum P_{R}}{\sum\left(t_{s t}\right)-\sum\left(t_{s p}\right)}
$$

Where, $\mathrm{P}_{\mathrm{R}}-$ Received Packet Size, $\mathrm{t}_{\mathrm{st}}-$ Start Time, $\mathrm{t}_{\mathrm{sp}}-$ Stop Time.

Unit - Kbps (Kilo bits per second)

\subsection{Packet Delivery Ratio (PDR)}

It is the ratio of number of packets received at the destination to the number of packets generated at the source. A network should work to attain high PDR in order to have a better performance. PDR shows the amount of reliability offered by the network.

$$
\mathrm{PDR}=\left(\frac{\sum N_{R}}{\sum N_{G}}\right) X 100
$$

Where, $\mathrm{N}_{\mathrm{R}}-$ Number of Received Packets, $\mathrm{N}_{\mathrm{G}}-$ Number of Generated Packets

Unit - Percentage ratio (\%).

\subsection{Average End - to - Delay}

This is the average time delay consumed by data packets to propagate from source to destination. This delay includes the total time of transmission i.e. propagation time, queuing time, route establishment time etc. A network with minimum average end to end delay offers better speed of communication.

$$
\text { Average End - to - End Delay }=\sum \mathrm{t}_{P R}-\sum t_{P S}
$$

Where, $t_{\mathrm{PR}}-$ Packet Receive Time, $\mathrm{t}_{\mathrm{PS}}-$ Packet Send Time 
Unit - Milli Seconds (ms).

\section{DATA TRAFFIC /APPLICATION TRAFFIC TYPES}

Data and traffic agent that takes the responsibility to transport the data in the network are of different types and offer different characteristics in the network $[10,17,18]$. It is necessary to understand the characteristics and therefore the performance to find the suitability of each type in a network. The two types of data/traffic agent types used in the network are as follows:

\subsection{TCP/FTP}

In such a traffic scenario, TCP represents the data type and FTP represents the application traffic agent of any application which transports TCP data. Here TCP is a transport layer protocol and FTP is an application layer protocol. This scenario offers connection oriented transmission environment, where communication occurs in phases, namely, connection establishment, data transmission, connection termination. The three basic characteristics offered are:

(a) Reliable: TCP/FTP offers reliable communication, as it offers guaranteed delivery of data by employing the acknowledgements which guarantees the delivery of data at a destination. In case acknowledgements are not received till the timeout period, retransmissions are made to ensure the delivery of data at the receiver. We can say that positive acknowledgements, timeouts, and retransmissions are required to guarantee the delivery of data in a network.

(b) Bi-directional: Here in TCP/FTP, in one direction i.e. the forward direction, the sender transmits the data and in the other direction i.e. the reverse direction, the receiver acknowledges the sender by transmitting acknowledgements. So, in this way bi-directional communication occurs.

(c) Conforming: The network while working with TCP/FTP, offers conforming nature. The network is conforming in the context of transmissions as it offers both flow and congestion control. Flow control by preventing overflow of recipient buffer, and congestion control by keeping the track of acknowledgements, time outs, and retransmissions.

\subsection{UDP/CBR}

This type of traffic implies data of UDP type and application traffic agent is CBR. Here, the former is a transport layer protocol and latter is application layer protocol. It offers transmission of data at constant bit rate and does not communicate in phases, and traffic moves in one direction from source to destination without any feedback from destination. It offers three basic characteristics mentioned below:

(a) Unreliable: The network is quiet unreliable as it does not set up communication in phases and does not rely on acknowledgements to recover the lost messages. The sender node does not take the responsibility of the successful delivery of data.

(b) Unidirectional: As no acknowledgements are transmitted from receiver, only one way communication is done i.e. on the forward link. The destination does not send any data packet to the receiver, therefore it offers unidirectional traffic. (c) Predictable: The UDP/CBR has predictable nature of transmission, as it offers constant bit rate, fixed and known packet size, fixed and known packet interval, and fixed and known packet stream duration.

\section{SIMULATION ENVIRONMENT}

The operating system that is used to support the simulation described in this paper is Linux (Ubuntu 10.10). The simulation tool is Network Simulator-2 (NS-2.34), which is a discrete event simulator. This simulator needs operating system that supports g++ system files, that is offered by Linux or UNIX and not by windows which on the other side supports .exe system file. Linux is used; as it offers both graphical user interfaces (GUI) and command line interface (CLI), whereas UNIX offers only CLI. The simulation of a MANET is done for AODV routing protocol, and the impact of variation in the parameters like, simulation time, number of nodes, and speed of mobile nodes are observed on the network.

\section{SIMULATION MODELS}

There are three simulation models specified in this paper. These models specify the various parameters and their values that are used for TCP/FTP and UDP/CBR connection environment for the three aforementioned variations.

\subsection{Simulation Model I: Varying Simulation Time}

The following table 1 specifies the parameters used for varying simulation time network model.

Table 1. Parameters for Model I

\begin{tabular}{|c|c|c|}
\hline \multirow[b]{2}{*}{ Parameters } & \multicolumn{2}{|c|}{ Values } \\
\hline & TCP/FTP & UDP/CBR \\
\hline Traffic Agent Type & FTP & CBR \\
\hline Data Type & TCP & UDP \\
\hline Channel & Wireless & Wireless \\
\hline Network Size & $\begin{array}{c}800 \mathrm{~m} \text { X 600m } \\
(\mathrm{x} \text { X y })\end{array}$ & $\begin{array}{c}800 \mathrm{~m} \text { X 600m } \\
(\mathrm{x} \text { X y })\end{array}$ \\
\hline Routing Protocol & AODV & AODV \\
\hline Number of nodes & 30 & 30 \\
\hline $\begin{array}{c}\text { Speed of mobile } \\
\text { nodes }\end{array}$ & Random & Random \\
\hline Simulation time & $\begin{array}{l}20 \text { to } 1000 \\
\text { seconds }\end{array}$ & $\begin{array}{l}20 \text { to1000 } \\
\text { seconds }\end{array}$ \\
\hline
\end{tabular}

\subsection{Simulation Model II: Varying Number of Nodes}

The following table specifies the parameters used for varying number of nodes implemented in this network model to test the performance of the network. As these values are important for figuring out the results, these observations are provided in Table 2 which is given below: 
Table 2. Parameters for Model II

\begin{tabular}{|c|c|c|}
\hline \multirow{2}{*}{ Parameters } & \multicolumn{2}{|c|}{ Values } \\
\cline { 2 - 3 } & TCP/FTP & UDP/CBR \\
\hline Traffic Agent Type & FTP & CBR \\
\hline Data Type & TCP & UDP \\
\hline Channel & Wireless & Wireless \\
\hline Network Size & $\begin{array}{c}800 \mathrm{~m} \mathrm{X} \mathrm{600m} \\
\text { (x X y ) }\end{array}$ & $\begin{array}{c}800 \mathrm{~m} \mathrm{X} \mathrm{600m} \\
(\mathrm{x} X \mathrm{y})\end{array}$ \\
\hline Routing Protocol & AODV & AODV \\
\hline $\begin{array}{c}\text { Number of nodes } \\
\text { Speed of mobile } \\
\text { nodes }\end{array}$ & $\begin{array}{c}10.33 \mathrm{~m} / \mathrm{sec} \text { Or } 100 \\
120 \mathrm{~km} / \mathrm{hr}\end{array}$ & $\begin{array}{c}33.33 \mathrm{~m} / \mathrm{sec} \text {. Or } \\
120 \mathrm{~km} / \mathrm{hr}\end{array}$ \\
\hline $\begin{array}{c}\text { Simulation time } \\
1000 \mathrm{~seconds}\end{array}$ & $1000 \mathrm{~seconds}$ \\
\hline
\end{tabular}

\subsection{Simulation Model III: Varying Speed} of Mobile Nodes

The following table specifies the parameters used for varying speed of mobile nodes implemented in this network model to test the performance of the network. These are provided in Table 3 which is given below:

Table 3. Parameters for Model III

\begin{tabular}{|c|c|c|}
\hline \multirow[b]{2}{*}{ Parameters } & \multicolumn{2}{|c|}{ Values } \\
\hline & TCP/FTP & UDP/CBR \\
\hline Traffic Agent Type & FTP & CBR \\
\hline Data Type & $\mathrm{TCP}$ & UDP \\
\hline Channel & Wireless & Wireless \\
\hline Network Size & $\begin{array}{c}800 \mathrm{~m} \text { X 600m } \\
(\mathrm{x} \mathrm{X} \mathrm{y})\end{array}$ & $\begin{array}{c}800 \mathrm{~m} \mathrm{X} \mathrm{600m} \\
(\mathrm{x} \text { X y })\end{array}$ \\
\hline Routing Protocol & AODV & AODV \\
\hline Number of nodes & 30 nodes & 30 nodes \\
\hline $\begin{array}{c}\text { Speed of mobile } \\
\text { nodes }\end{array}$ & $\begin{array}{c}5.55 \mathrm{~m} / \mathrm{sec} \text { or } 20 \\
\mathrm{~km} / \mathrm{hr} \text { to } 33.33 \\
\mathrm{~m} / \mathrm{sec} \text { or } 120 \\
\mathrm{~km} / \mathrm{hr}\end{array}$ & $\begin{array}{c}5.55 \mathrm{~m} / \mathrm{sec} \text { or } \\
20 \mathrm{~km} / \mathrm{hr} \text { to } \\
33.33 \mathrm{~m} / \mathrm{sec} \text { or } \\
120 \mathrm{~km} / \mathrm{hr}\end{array}$ \\
\hline Simulation time & 1000 seconds & 1000 seconds \\
\hline
\end{tabular}

\section{EXPERIMENTAL RESULTS AND OBSERVATIONS}

The following tables show the observations taken for the various variations, and their effect on the three performance metrics for both TCP/FTP, and UDP/CBR. The results are provided through graphs plotted as Performance metrics vs. varying parameters (e.g. Throughput vs. Simulation time).

\subsection{Observation Table I}

The observations obtained by implementing model I for the two traffic scenarios is provided in Table 4.

Table 4. Observations for Varying Simulation Time

\begin{tabular}{|c|c|c|c|c|c|c|}
\hline \multirow{2}{*}{$\begin{array}{c}\text { Simul } \\
\text { ation } \\
\text { Time } \\
\text { (Seco } \\
\text { nds) }\end{array}$} & \multicolumn{2}{|c|}{$\begin{array}{l}\text { Throughput } \\
\text { (Kbps) }\end{array}$} & \multicolumn{2}{|c|}{$\begin{array}{c}\text { Packet } \\
\text { Delivery } \\
\text { Ratio (\%) }\end{array}$} & \multicolumn{2}{|c|}{$\begin{array}{l}\text { Average End } \\
\text { to End Delay } \\
\text { (milliseconds) }\end{array}$} \\
\hline & $\begin{array}{l}\text { TCP/ } \\
\text { FTP }\end{array}$ & $\begin{array}{l}\text { UDP/ } \\
\text { CBR }\end{array}$ & $\begin{array}{l}\text { TCP/ } \\
\text { FTP }\end{array}$ & $\begin{array}{l}\mathrm{UDP} / \\
\mathrm{CBR}\end{array}$ & $\begin{array}{l}\text { TCP/ } \\
\text { FTP }\end{array}$ & $\begin{array}{l}\text { UDP/ } \\
\text { CBR }\end{array}$ \\
\hline 20 & 422 & 64 & 93.88 & 94.58 & 760.2 & 304.5 \\
\hline 100 & 478 & 72 & 97.08 & 97.40 & 730.6 & 75.19 \\
\hline 200 & 460 & 74 & 97.76 & 98.2 & 753.9 & 75.11 \\
\hline 300 & 439 & 74 & 98.04 & 98.62 & 803.2 & 43.67 \\
\hline 400 & 435.4 & 74 & 98.30 & 98.72 & 862.9 & 39.75 \\
\hline 500 & 433.3 & 74 & 98.41 & 98.86 & 901.0 & 37.79 \\
\hline 600 & 431 & 74 & 98.45 & 98.95 & 907.9 & 37.03 \\
\hline 700 & 431 & 74 & 98.52 & 99.02 & 911.6 & 36.28 \\
\hline 800 & 430 & 74 & 98.55 & 99.08 & 923.9 & 35.53 \\
\hline 900 & 431 & 74 & 98.58 & 99.11 & 920.2 & 35.08 \\
\hline 1000 & 428 & 74 & 98.57 & 99.11 & 934.3 & 34.47 \\
\hline
\end{tabular}

\subsubsection{Result I: Throughput vs. Simulation Time}

The following Figure 1 shows the response of throughput expressed in kbps against varying simulation time in seconds for the two traffic scenarios obtained by table 4 .

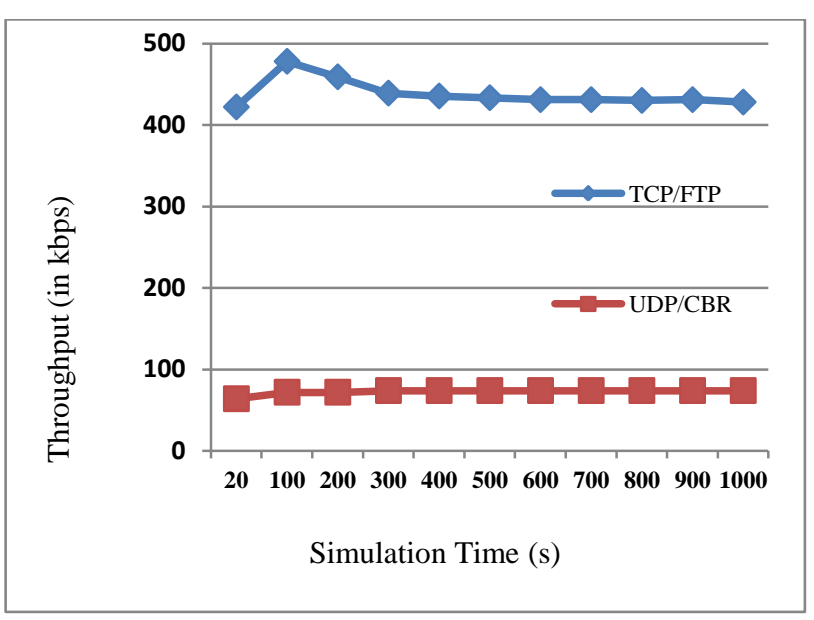

Fig. 1: Graph of Throughput vs. Simulation Time 


\subsubsection{Result II: Packet Delivery Ratio vs.}

\section{Simulation Time}

Based on the observations of table 4, the response of packet delivery ratio in $\%$ against varying simulation time in seconds is shown in Figure 2.

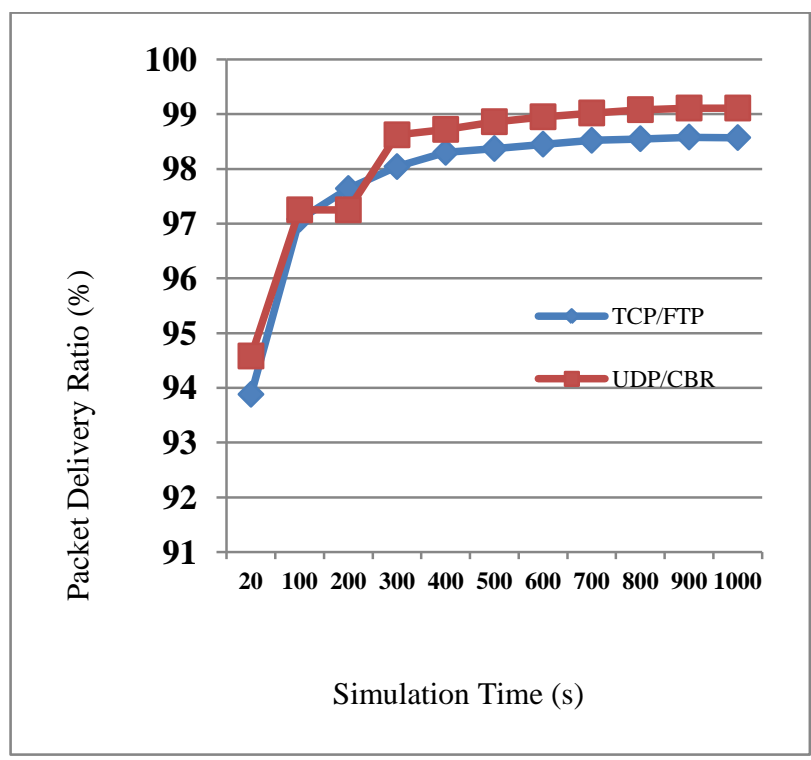

Fig. 2: Graph of Packet Delivery Ratio vs. Simulation Time

\subsubsection{Result III: Average End- to- End Delay vs.}

\section{Simulation Time}

Based on the observations of table 4, the response of average end - to - end delay in ms against varying simulation time in seconds is shown in Figure 3.

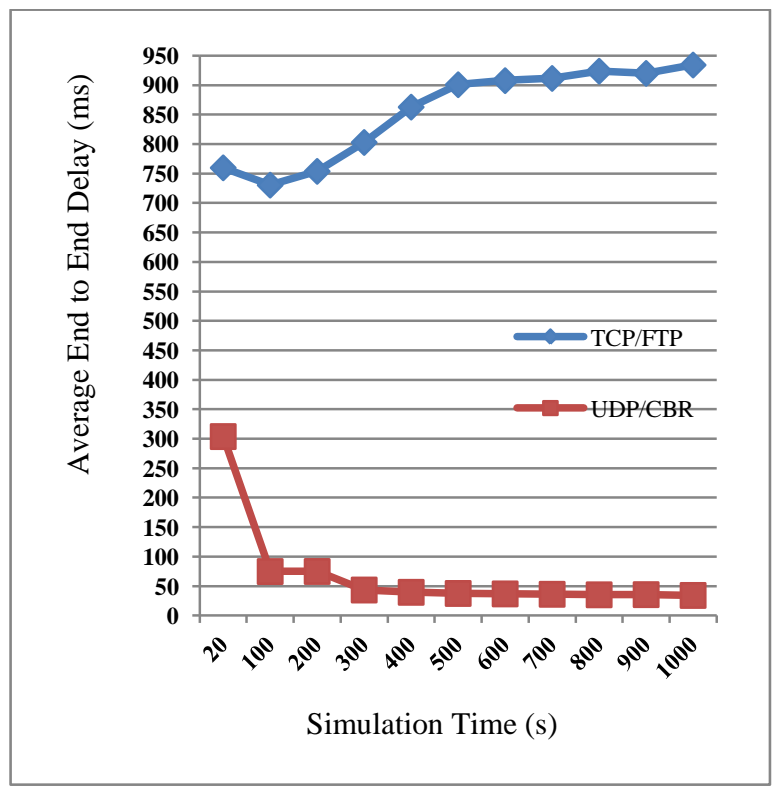

Fig. 3: Graph of Average End - to - End Delay vs. Simulation Time

\subsection{Observation Table II}

The observations taken on implementing model II for the two traffic scenarios is provided in Table 5. The results are based on these observations.
Table 5. Observations for Varying Number of Nodes

\begin{tabular}{|c|c|c|c|c|c|c|}
\hline \multirow{2}{*}{$\begin{array}{c}\text { Num } \\
\text { ber } \\
\text { of } \\
\text { node } \\
\text { s }\end{array}$} & \multicolumn{2}{|c|}{$\begin{array}{l}\text { Throughput } \\
\text { (Kbps) }\end{array}$} & \multicolumn{2}{|c|}{$\begin{array}{c}\text { Packet } \\
\text { Delivery Ratio } \\
(\%)\end{array}$} & \multicolumn{2}{|c|}{$\begin{array}{l}\text { Average End } \\
\text { to End Delay } \\
\text { (milliseconds) }\end{array}$} \\
\hline & $\begin{array}{l}\text { TCP/ } \\
\text { FTP }\end{array}$ & $\begin{array}{l}\mathrm{UDP} / \\
\mathrm{CBR}\end{array}$ & $\begin{array}{l}\text { TCP/ } \\
\text { FTP }\end{array}$ & $\begin{array}{l}\text { UDP/ } \\
\text { CBR }\end{array}$ & $\begin{array}{l}\text { TCP/ } \\
\text { FTP }\end{array}$ & $\begin{array}{l}\text { UDP/ } \\
\text { CBR }\end{array}$ \\
\hline 10 & 476 & 46 & 97 & 99 & 500 & 20 \\
\hline 20 & 580 & 90 & 97 & 98 & 646 & 40 \\
\hline 30 & 445 & 130 & 95 & 94 & 913 & 140 \\
\hline 40 & 472 & 157 & 94 & 87 & 950 & 302 \\
\hline 50 & 380 & 166 & 92 & 74 & 1116 & 1140 \\
\hline 60 & 991 & 140 & 97 & 51 & 362 & 3330 \\
\hline 70 & 853 & 125 & 97 & 40 & 387 & 4600 \\
\hline 80 & 1000 & 119 & 97 & 33 & 536 & 4440 \\
\hline 90 & 917 & 122 & 96 & 32 & 460 & 5745 \\
\hline 100 & 926 & 100 & 96 & 23 & 412 & 5588 \\
\hline
\end{tabular}

\subsubsection{Result I: Throughput vs. Number of Nodes} The following Figure 4 shows the response of throughput expressed in kbps against number of nodes for the two traffic scenarios obtained by table 5 .

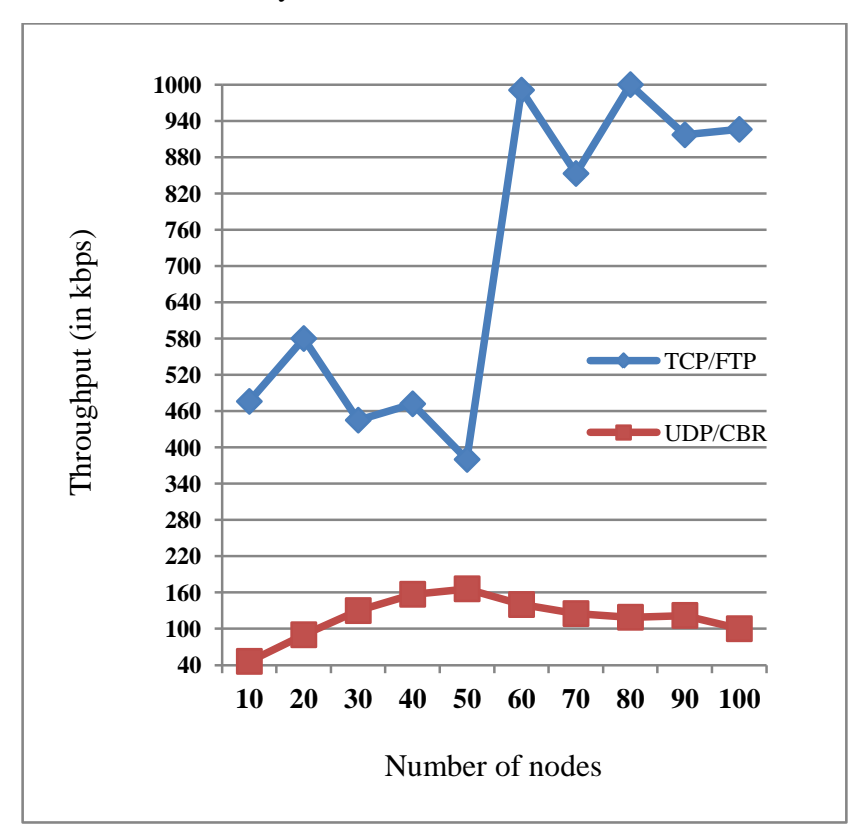

Fig. 4: Graph of Throughput vs. Number of Nodes 


\subsubsection{Result II: Packet Delivery Ratio vs. Number} of Nodes

Based on the observations of table 5, the response of packet delivery ratio in $\%$ against varying number of nodes is shown in Figure 5.

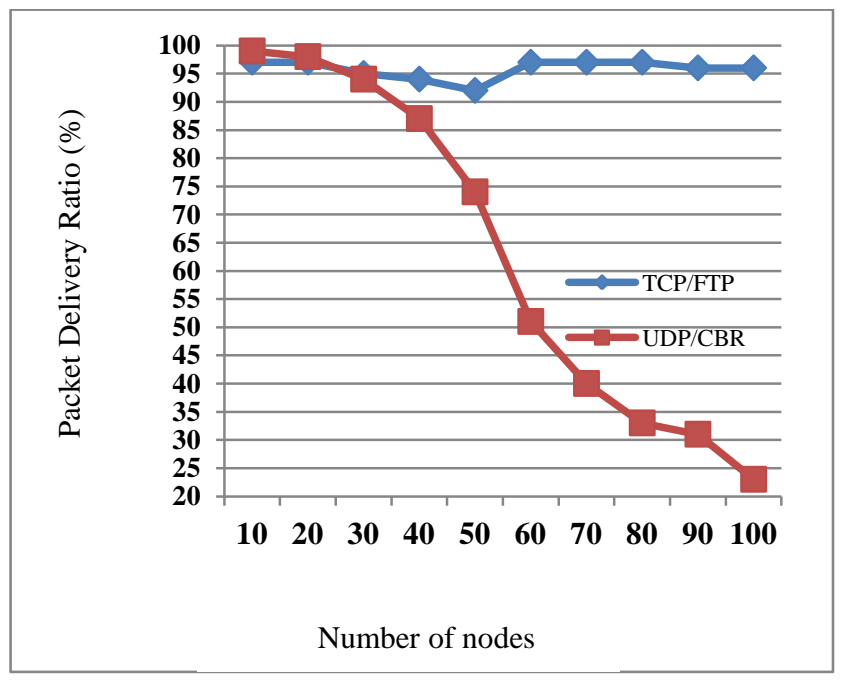

Fig. 5: Graph of Packet Delivery Ratio vs. Number of Nodes

8.2.3 Result III: Average End - to - End Delay vs. Number of Nodes

Based on the observations of table 5, the response of average end - to - end delay in ms against varying number of nodes is shown in Figure 6.

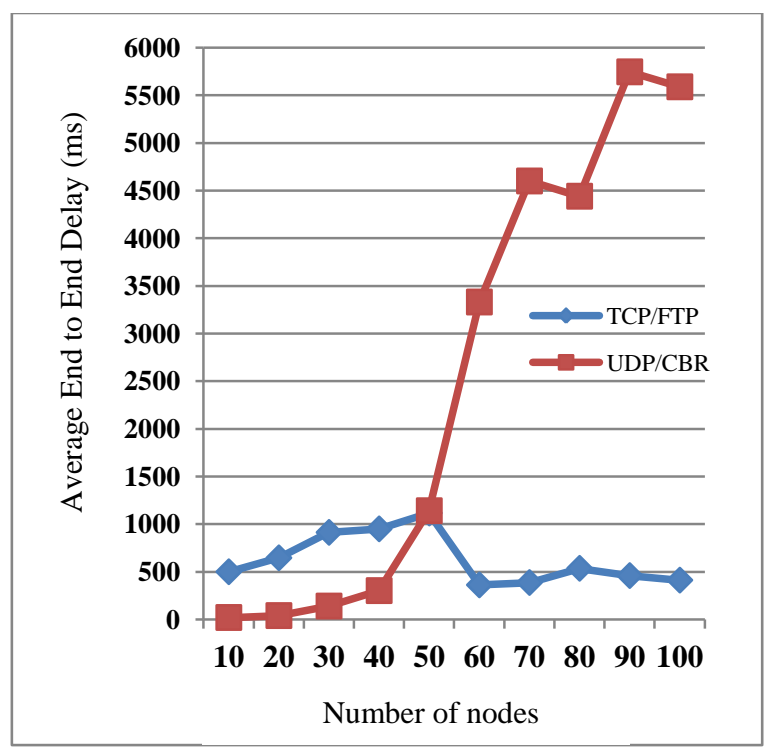

Fig. 6: Graph of Average End - to - End Delay vs. Number of Nodes

\subsection{Observation Table III}

The observations provided below are obtained by number of exhaustive simulations done to obtain a clear trend of the performance in a network. On the basis of these observations the response of the performance against the varying parameter for the two traffic scenarios is plotted. The observations are taken for the three performance metrics; throughput, packet delivery ratio and average end - to - end delay. The observations taken on implementing model III for the two traffic scenarios is provided below in Table 6 .

Table 6. Observations for Varying Speed of Mobile Nodes

\begin{tabular}{|c|c|c|c|c|c|c|}
\hline \multirow{2}{*}{$\begin{array}{c}\text { Speed of } \\
\text { mobile } \\
\text { nodes } \\
\text { (m/sec. } \\
\text { Or } \\
\text { km/hr) }\end{array}$} & \multicolumn{2}{|c|}{$\begin{array}{c}\text { Throughput } \\
\text { (Kbps) }\end{array}$} & \multicolumn{2}{|c|}{$\begin{array}{c}\text { Packet } \\
\text { Delivery } \\
\text { Ratio (\%) }\end{array}$} & \multicolumn{2}{|c|}{$\begin{array}{l}\text { Average End } \\
\text { to End Delay } \\
\text { (milliseconds } \\
\text { ) }\end{array}$} \\
\hline & $\begin{array}{l}\text { TCP } \\
/ \text { FTP }\end{array}$ & $\begin{array}{l}\text { UD } \\
\text { P/C } \\
\text { BR }\end{array}$ & $\begin{array}{c}\text { TCP } \\
/ \mathrm{FT} \\
\mathrm{P}\end{array}$ & $\begin{array}{l}\text { UDP/ } \\
\text { CBR }\end{array}$ & $\begin{array}{c}\text { TCP } \\
/ \mathrm{FT} \\
\mathrm{P}\end{array}$ & $\begin{array}{l}\mathrm{UDP} / \\
\mathrm{CBR}\end{array}$ \\
\hline 5.33 or 20 & 464 & 68 & 98 & 94 & 727 & 189 \\
\hline $\begin{array}{c}11.11 \text { or } \\
40\end{array}$ & 430 & 72 & 97 & 97 & 790 & 55 \\
\hline $\begin{array}{c}16.66 \text { or } \\
60\end{array}$ & 405 & 73 & 97 & 98 & 951 & 62 \\
\hline $\begin{array}{c}22.22 \text { or } \\
80\end{array}$ & 397 & 69 & 96 & 94 & 803 & 164 \\
\hline $\begin{array}{c}27.77 \text { or } \\
100\end{array}$ & 448 & 71 & 97 & 96 & 780 & 73 \\
\hline $\begin{array}{c}33.33 \text { or } \\
120\end{array}$ & 383 & 70 & 96 & 95 & 887 & 205 \\
\hline
\end{tabular}

\subsubsection{Result I: Throughput vs. Speed of Mobile Nodes}

The following Figure 7 shows the response of throughput expressed in kbps against speed of mobile nodes for the two traffic scenarios obtained by table 6 .

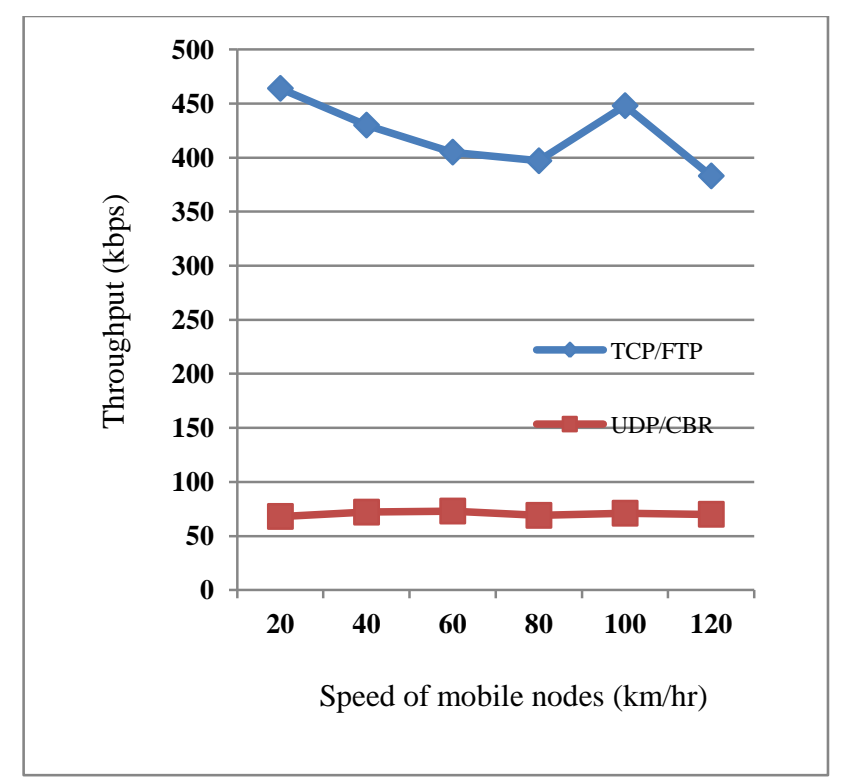

Fig. 7: Graph of Throughput vs. Speed of Mobile Nodes 


\subsubsection{Result II: Packet Delivery Ratio vs. Speed of} Mobile Nodes

Based on the observations of table 6 , the response of packet delivery ratio in $\%$ against varying speed of mobile nodes is shown in Figure 8.

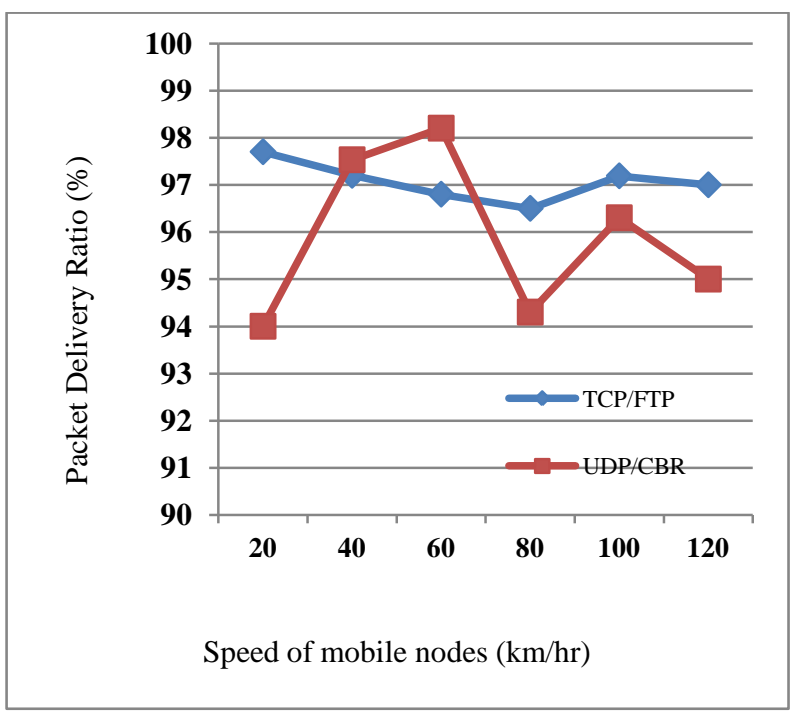

Fig. 8: Graph of Packet Delivery Ratio vs. Speed of Mobile Nodes

\subsubsection{Result III: Average End - to - End Delay vs. Speed of Mobile Nodes}

Based on the observations of table 6, the response of average end - to - end delay in ms against varying speed of mobile nodes is shown in Figure 9.

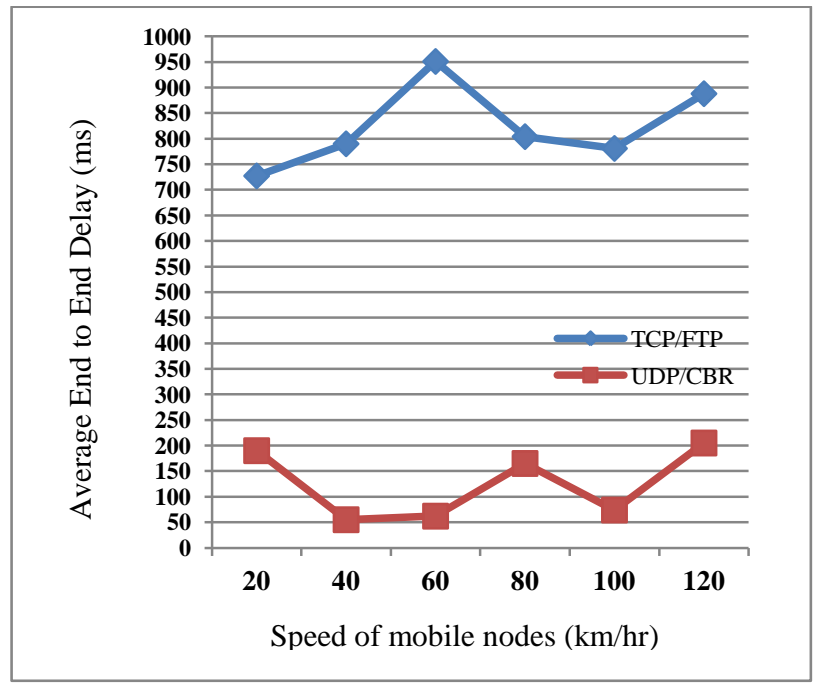

Fig. 9: Graph of Average End - to - End Delay vs. Speed of Mobile Nodes

\section{CONCLUSIONS AND FUTURE SCOPE}

The conclusions presented in this paper compare the two traffic scenarios that are TCP/FTP and UDP/CBR, implemented in the network under test. To find the suitability from these two available traffics in a network in various environments, the results are compared and necessary conclusions are made. The paper is concluded on the basis of performance offered by the traffic patterns for the three performance metrics considered. The various conclusions drawn from various experiments, observations, and analysis done in the paper are as follows:

Throughput: Out of the two traffic types i.e. TCP/FTP and $\mathrm{UDP} / \mathrm{CBR}$, the former one provides far better performance than the latter. This proves that the network working with AODV provides better efficiency with TCP/FTP than UDP/CBR.

Packet Delivery Ratio (PDR): Although the PDR of UDP/CBR has greater maximum and minimum values than TCP/FTP, the latter offers almost a constant trend, whereas, the former offers highly varying (rising and falling trends), in all the three scenarios. Therefore, TCP/FTP is more reliable than UDP/CBR.

Average End to End Delay: The UDP/CBR offers lesser, average end to end delay, than TCP/FTP, therefore better speed of transmission, but as an exception in the scenario of number of nodes, as the density of nodes increases, the average end - to - end delay also increases and the speed of transmission decreases. For future extensions in this work, the concept can be used with various variants of TCP to give a comprehensive performance analysis for various other reactive protocols and performance metrics.

\section{REFERENCES}

[1] Panagiotis Papadimitratos and Zugmunt J. Haas, "Secure routing for Mobile Ad Hoc Networks", In Proceedings of the SCS Communication Networks and Distributed Systems Modeling and Simulation Conference (CNDS2002), San Antonio, TX, January 27-31, 2002.

[2] Sunil Taneja and Ashwani Kush, "A Survey of Routing Protocols in Mobile Ad Hoc Networks", International Journal of Innovation, Management and Technology, Vol. 01, No. 03, August 2010, 279-285.

[3] GS. Mamatha and Dr. S.C. Sharma, "Analyzing MANET Variations, Challenges, Capacity and Protocol Issues", International Journal of Computer Science and Engineering Survey (IJCSES), Vol. 1, No.1, August 2010, 14-21.

[4] G. Vijaya Kumar, Y Vasudev Reddyr, Dr. M. Nagendra, "Current Research Work on Routing Protocols for MANET: A Literature Survey", International Journal on Computer Science and Engineering, Vol. 02, No. 03, 2010, 706-713.

[5] Jun-Zhao Sun, "Mobile Ad Hoc Networking: An Essential Technology for Pervasive Computing", InfoTech and Info-net, 2001. Proceedings. ICII 2001Beijing.2001 International conference, 2001, Vol. No. 03, 316-321.

[6] Imrich Chlamtac, Marco Conti, Jennifer J-N Liu, "Mobile Ad Hoc Networking-Imperatives and Challenges", Elsevier, 2003, 13-64.

[7] Priyanka Goyal, Vinti Parmar, Rahul Rishi, "MANET: Vulnerabilities, Challenges, Attacks, Applications", International Journal of Computational Engineering \& Management, Vol. 11, January 2011, 32-37.

[8] Jiazi YI, "A Survey on the Applications of MANET", Polytech' Nantes, February 2008.

[9] A Rahim, I Ahmed, Z S Khan, M Sher, M Shoaib, A Javed, R Mahmood, "A Comparative Study of Mobile and Vehicular Ad Hoc Networks", International Journal 
of Recent Trends in Engineering, Vol. 02, No. 04, November 2009. 195-197.

[10] Bijan Paul, Md. Ibrahim, Md. Abu Naser Bikas, "Experimental Analysis of AODV \& DSR over TCP \& CBR Connections with Varying Speed and Node Density in VANET", International Journal of Computer Applications, Vol. 24, No. 4, June 2011.

[11] Muhammad Inayat Ullah, Nasir Nawaz, "Measuring the Effect of CBR and TCP Traffic Models over DYMO Routing Protocol", Global Journal of Computer Science and Technology, Vol. 11 Issue 14.

[12] Md. Monzur Morshed, Meftah Ur Rahman, Md. Rafiqul Islam: An Empirical Study of UDP (CBR) Packet Performance over AODV Single \& Multi-Channel Parallel Transmission in MANET. CoRR abs/1109.6502 (2011)

[13] Vikas Singla, Ajay Kumar, Rakesh Singla, "CBR and TCP Based Performance Comparison of Various Protocols of MANET: A Review", National Journal on Advances in Computing and Management, Vol. 1, No. 2, October 2010.
[14] Deepti Verma, Deepika Chandrawanshi, "Comparative Performance Evaluation of AODV over CBR and TCP Traffic", IJCST, Vol. 2, Issue 2 June 2011.

[15] V.R. Sarna Dhulipala, R.M. Chandrasekran, R. Prabakaran, "Timing Analysis and Repeatability Issues of Mobile Ad Hoc Networking Applications Traffic", International Journal of Recent Trends in Engineering, Vol.1, No.1 May 2009.

[16] Ajay Kumar, Ashwani Kumar Singla, "Performance Evaluation of MANET routing protocols on the basis of TCP Traffic pattern", International Journal of Information Technology Convergence and Services (IJITCS), Vol. 1, No. 5, October 2011.

[17] Thomas Clausen, Philip Jacquet, Laurent Viennot, "Comparative Study of CBR and TCP Performance of MANET Routing Protocols", Mindpass Center for Distributed Systems.

[18] Vikas Singla, Parveen Kakkar, "Traffic Pattern based performance Comparison of Reactive and Proactive Protocols of Mobile Ad Hoc Networks", International Journal of Computer Applications, Vol. 5, No. 10, August'2010. 